\title{
Brain Distribution of a Panel of Epidermal Growth Factor Receptor Inhibitors Using Cassette Dosing in Wild-Type and Abcb1/Abcg2- Deficient Mice ${ }^{\llbracket}$
}

\author{
Minjee Kim, Janice K. Laramy, Afroz S. Mohammad, Surabhi Talele, James Fisher, \\ Jann N. Sarkaria, and William F. Elmquist

\begin{abstract}
Brain Barriers Research Center, Department of Pharmaceutics, College of Pharmacy (M.K., J.K.L., A.S.M., S.T., W.F.E.) and Clinical Pharmacology and Analytical Services Laboratory, Department of Experimental and Clinical Pharmacology (J.F.), University of Minnesota, Minneapolis, Minnesota; and Radiation Oncology, Mayo Clinic, Rochester, Minnesota (J.N.S.)
\end{abstract}

Received August 28, 2018; accepted January 28, 2019

\begin{abstract}
Tyrosine kinase inhibitors that target the epidermal growth factor receptor (EGFR) have had success in treating EGFR-positive tumors, including non-small-cell lung cancer (NSCLC). However, developing EGFR inhibitors that can be delivered to the brain remains a challenge. To identify optimal compounds for brain delivery, eight EGFR inhibitors [afatinib, 6-[4-[(4-ethylpiperazin-1-yl)methyl]phenyl]-N-(1-phenylethyl)-7H-pyrrolo[2,3-day]pyrimidin-4-amine (AEE788), [4-(3-chloro-2fluoroanilino)-7-methoxyquinazolin-6-yl] (2R)-2,4-dimethylpiperazine1-carboxylate (AZD3759), erlotinib, dacomitinib, gefitinib, osimertinib, and vandetanib] were evaluated for distributional kinetics using cassette dosing with the ultimate goal of understanding the brain penetrability of compounds that share the same molecular target in an important oncogenic signaling pathway for both primary brain tumors (glioblastoma) and brain metastases (e.g., NSCLC). Cassette dosing
\end{abstract}

was validated by comparing the brain-to-plasma ratios obtained from cassette-dosing to discrete-dosing studies. The brain-to-blood partition coefficients $\left(K_{p, b r a i n}\right)$ were calculated following cassette dosing of the eight EGFR inhibitors. The comparison of $K_{p, b r a i n}$ in wild-type and transporter-deficient mice confirmed that two major efflux transporters at the blood-brain barrier (BBB), P-glycoprotein and breast cancer resistance protein, play a crucial role in the brain distribution of seven out of eight EGFR inhibitors. Results show that the prediction of brain distribution based on physicochemical properties of a drug can be misleading, especially for compounds subject to extensive efflux transport. Moreover, this study informs the choice of EGFR inhibitors, i.e., determining BBB permeability combined with a known target potency, that may be effective in future clinical trials for brain tumors.

\section{Introduction}

The epidermal growth factor receptor (EGFR) has been a useful biomarker and an attractive drug target in the treatment of various tumors (Doroshow, 2005; Seshacharyulu et al., 2012). EGFR is often found to be constitutively activated due to gene mutation and/or amplification, leading to typical oncogenic behavior, including increased cell survival, proliferation, and invasion (Bertotti et al., 2009; Seshacharyulu et al., 2012). EGFR-tyrosine kinase inhibitors have been developed for use as first-line therapies for patients, especially those with non-small-cell lung cancer (NSCLC), and they have shown promising efficacy in patient populations that overexpress EGFR (Doroshow, 2005). Patients with NSCLC have a substantial risk of developing metastases in the central

This work was supported by the National Institutes of Health [Grants RO1 CA138437, RO1 NS077921, U54 CA210181, U01 CA227954, and P50 CA108960].

https://doi.org/10.1124/dmd.118.084210.

S This article has supplemental material available at dmd.aspetjournals.org. nervous system (CNS) (Rangachari et al., 2015; McCoach et al., 2016). CNS metastases often develop even when extracranial disease sites are controlled using standard regimens. The first generation of EGFR inhibitors, erlotinib and gefitinib, have shown some success in treating NSCLC patients with peripheral lesions, but these drugs have had limited success in treating brain metastases of NSCLC, potentially due to limited delivery to the CNS (Kawamura et al., 2009; Agarwal et al., 2010, 2013; Weber et al., 2011; de Vries et al., 2012). Therefore, there has been a great interest in developing brain penetrant EGFR inhibitors for treating brain metastases.

While there is a clear rationale for using EGFR inhibitors in treating brain metastases, there has also been great interest in treating primary brain tumors with EGFR inhibitors. Approximately $60 \%$ of glioblastomas, the most common and aggressive type of primary brain tumor, are often found to have EGFR overexpression (Ohgaki and Kleihues, 2007; Huang et al., 2009; Brennan et al., 2013). Moreover, overexpression of EGFR is closely related to a more aggressive glioblastoma phenotype (Shinojima et al., 2003). Despite this, EGFR inhibitors have shown no significant benefit in glioblastoma patients (Rich et al., 2004; van den

ABBREVIATIONS: AEE788, 6-[4-[(4-ethylpiperazin-1-yl)methyl]phenyl]- $N$-(1-phenylethyl)-7H-pyrrolo[2,3-day]pyrimidin-4-amine; AUC, area under the curve; AZD3759, [4-(3-chloro-2-fluoroanilino)-7-methoxyquinazolin-6-yl] (2R)-2,4-dimethylpiperazine-1-carboxylate; BBB, blood-brain barrier; BCRP, breast cancer resistance protein; CNS, central nervous system; DA, distribution advantage; DMSO, dimethylsulfoxide; EGFR, epidermal growth factor receptor; FVB, Friend leukemia virus strain B; LC-MS/MS, liquid chromatography-tandem mass spectrometry; Mdr1, multidrug resistance protein 1 (p-glycoprotein); MPO, multiparameter optimization; NCA, noncompartmental analysis; NSCLC, non-small-cell lung cancer; P-gp, P-glycoprotein; TKO, triple-knockout; WT, wild-type. 
Bent et al., 2009) and have not led to regulatory approval of any EGFR inhibitor for the treatment of glioblastoma. One important factor to consider in examining reasons for the limited efficacy of these drugs in the CNS is that the delivery of many early EGFR inhibitors has shown to be insufficient to elicit a response at the target site in the CNS. Moreover, many of the early-generation inhibitors are substrates of the major efflux transporters, P-glycoprotein (P-gp) and breast cancer resistance protein (Bcrp), that may lead to limited brain penetration at the blood-brain barrier (BBB), especially in intratumoral regions that have an intact BBB in metastases (Lockman et al., 2010) and primary tumor (Sarkaria et al., 2018).

In the current study, we examined the distribution to the brain of a set of EGFR inhibitors, including early-generation inhibitors (erlotinib, gefitinib, and afatinib) and more recently developed inhibitors [osimertinib, vandetanib, [4-(3-chloro-2-fluoroanilino)-7-methoxyquinazolin-6yl] (2R)-2,4-dimethylpiperazine-1-carboxylate (AZD3759), dacomitinib, and 6-[4-[(4-ethylpiperazin-1-yl)methyl]phenyl]- $N$-(1-phenylethyl)-7Hpyrrolo[2,3-day]pyrimidin-4-amine (AEE788)] (Fig. 1; Table 1). These eight EGFR inhibitors were chosen based on previous and possible future use in patients with brain tumors. In addition, based on the few preclinical studies with these drugs, this series of EGFR inhibitors was chosen with the intention of having a wide range of BBB permeability.

Brain distributional kinetics were examined by using a cassette-dosing strategy. Cassette-dosing studies are typically performed by coadministering a low dose of multiple compounds to a single animal to calculate pharmacokinetic parameters and metrics of individual compounds from the concentration-time pharmacokinetic profile (Manitpisitkul and White, 2004). As such, multiple concentration-time profiles of individual drugs can be obtained in a single animal. One of the benefits of using a cassettedosing strategy is that throughput of the study is significantly increased, and the number of animals that are used for the study is significantly reduced. This is especially true in pharmacokinetic and brain distribution studies with mice that are often conducted using a destructive sampling strategy and may require numerous animals for a single study with a single agent. Another interesting aspect of using cassette dosing to determine the CNS distribution of a series of compounds is that the brain

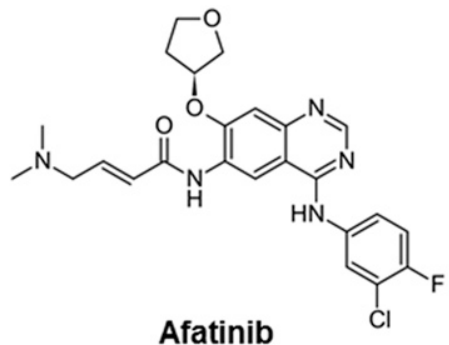<smiles>COc1cc2ncnc(Nc3cccc(Cl)c3F)c2cc1OC(=O)N1CCN(C)C[C@@H]1C</smiles>

AZD3759<smiles>C#Cc1cccc(Nc2ncnc3cc(OCCOC)c(OCCOC)cc23)c1</smiles>

Erlotinib<smiles>C=CC(=O)Nc1cc(Nc2nccc(-c3cn(C)c4ccccc34)n2)c(OC)cc1N(C)CCN(C)C</smiles>

Osimertinib<smiles>CCN1CCN(Cc2ccc(-c3cc4c(N[C@H](C)c5ccccc5)ncnc4[nH]3)cc2)CC1</smiles><smiles>COc1cc2ncnc(Nc3ccc(F)c(Cl)c3)c2cc1NC(=O)/C=C/CN1CCCCC1</smiles>

Dacomitinib<smiles>COc1cc2ncnc(Nc3ccc(F)c(Cl)c3)c2cc1OCCCN1CCOCC1</smiles>

Gefitinib<smiles>COc1cc2c(Nc3ccc(Br)cc3F)ncnc2cc1OCC1CCN(C)CC1</smiles>

Fig. 1. Structures of EGFR inhibitors used in the current study. 
TABLE 1

Physicochemical properties of EGFR inhibitors used in the study

\begin{tabular}{|c|c|c|c|c|c|c|c|c|}
\hline Compound & Type & $\mathrm{MW}^{a}$ & $\operatorname{clog} \mathrm{P}^{b}$ & $\operatorname{clog} \mathrm{D}^{b}$ & TPSA $^{a}$ & $\mathrm{HBD}^{a}$ & $\mathrm{pK}_{\mathrm{a}}^{b}$ & Efflux Liability \\
\hline AEE788 & Reversible $^{c}$ & 441 & 4.44 & 3.49 & 60 & 2 & 8.24 & Not reported \\
\hline Afatinib & Irreversible $^{d}$ & 486 & 3.76 & 2.34 & 89 & 2 & 8.81 & P-gp and Bcrp ${ }^{e}$ \\
\hline AZD3759 & NA & 460 & 4.03 & 3.86 & 80 & 1 & 7.10 & Not a substrate ${ }^{f}$ \\
\hline Dacomitinib & Irreversible $^{g}$ & 470 & 4.71 & 3.53 & 79 & 2 & 8.55 & Not reported \\
\hline Erlotinib & Reversible $^{h}$ & 393 & 3.20 & 3.20 & 75 & 1 & 4.62 & P-gp and Bcrp ${ }^{i}$ \\
\hline Gefitinib & Reversible $^{h}$ & 447 & 3.75 & 3.64 & 69 & 1 & 6.85 & P-gp and Bcrp ${ }^{j}$ \\
\hline Osimertinib & Irreversible $^{k}$ & 500 & 4.49 & 3.01 & 88 & 2 & 8.87 & P-gp and Bcrp ${ }^{e}$ \\
\hline Vandetanib & NA & 475 & 4.54 & 2.81 & 60 & 1 & 9.13 & P-gp and Bcrp ${ }^{l}$ \\
\hline
\end{tabular}

HBD, hydrogen bond donor and acceptor count; MW, molecular weight; NA, not available; TPSA, topological polar surface area.

${ }^{a}$ Obtained from PubChem (https://pubchem.ncbi.nlm.nih.gov/).

${ }^{b}$ Obtained from ChemAxon (https://chemicalize.com/).

${ }^{c}$ Reardon et al. (2012).

${ }^{d}$ Solca et al. (2012)

${ }^{e}$ Ballard et al. (2016).

${ }^{f}$ Zeng et al. (2015).

${ }^{g}$ Engelman et al. (2007).

${ }^{h}$ Krawczyk et al. (2017)

${ }^{i}$ Agarwal et al. (2013).

${ }^{j}$ Agarwal et al. (2010)

${ }^{k}$ Cross et al. (2014).

lMinocha et al. (2012)

penetration of different compounds can be examined within a single animal under identical physiologic conditions, including blood flow, BBB surface area, tight junction integrity, transporter expression, and function. The most common concern with the cassette-dosing strategy is regarding the possibility of drug-drug interactions due to coadministration of multiple drugs at the same time. However, several studies have reported that drug-drug interactions at the $\mathrm{BBB}$ are unlikely to happen in cassette dosing due to low dosages used in the study (1 to $2 \mathrm{mg} / \mathrm{kg}$ ) (Manitpisitkul and White, 2004; Liu et al., 2012) relative to the capacity of the transport systems (Cordon-Cardo et al., 1989; Cooray et al., 2002).

We examined the extent of brain penetration of these eight EGFR inhibitors by calculating area under the curve (AUC) ratios in brain and plasma following cassette dosing. To ensure there were no drug-drug interactions at the BBB, we also performed discrete-dosing studies for individual drugs and compared the brain-to-plasma ratios at two time points ( 1 and 8 hours post dose) with the results from the cassette-dosing study. Pharmacokinetic parameters and metrics were calculated from concentration-time profiles of each drug from cassette-dosing studies. The correlation between the CNS multiparameter optimization (MPO) score (Wager et al., 2010, 2016) and the measured brain penetration of these compounds was examined to determine the relationship between various physicochemical properties taken together in a series of EGFR inhibitors.

\section{Materials and Methods}

Chemicals and Reagents. AEE788 and AZD3759 were purchased from Selleck Chemicals (Houston, TX). $N$-[2-[2-(dimethylamino)ethyl-methylamino]4-methoxy-5-[[4-(1-methylindol-3-yl)pyrimidin-2-yl]amino]phenyl]prop-2enamide (osimertinib), $\mathrm{N}$-(3-chloro-4-fluorophenyl)-7-methoxy-6-(3-morpholin4-ylpropoxy)quinazolin-4-amine (gefitinib), $\mathrm{N}$-(4-bromo-2-fluorophenyl)-6methoxy-7-[(1-methylpiperidin-4-yl)methoxy]quinazolin-4-amine (vandetanib), $N$-(3-ethynylphenyl)-6,7-bis(2-methoxyethoxy)quinazolin-4-amine;hydrochloride (erlotinib hydrochloride), and (E)- $N$-[4-(3-chloro-4-fluoroanilino)-7methoxyquinazolin-6-yl]-4-piperidin-1-ylbut-2-enamide (dacomitinib) were purchased from LC Laboratories (Woburn, MA). (E)- $N$-[4-(3-chloro-4-fluoroanilino)7-[(3S)-oxolan-3-yl]oxyquinazolin-6-yl]-4-(dimethylamino)but-2-enamide (afatinib), $\left[{ }^{13} \mathrm{C},{ }^{2} \mathrm{H}_{3}\right]$-osimertinib, $\left[{ }^{2} \mathrm{H}_{8}\right]$-gefitinib, $\left[{ }^{13} \mathrm{C},{ }^{2} \mathrm{H}_{6}\right]$-vandetanib, $\left[{ }^{2} \mathrm{H}_{6}\right]$-erlotinib $\mathrm{HCl}$, and $\left[{ }^{2} \mathrm{H}_{6}\right]$-afatinib were purchased from Alsachim SAS (Illkirch, France). Analytic-grade reagents were purchased from Fisher Scientific (Waltham, MA). The rapid equilibrium dialysis device, including a 96-well base plate and membrane inserts (8-kDa molecular mass cutoff cellulose dialysis membrane), was purchased from Thermo Fisher Scientific Inc.
Animals. Animals for pharmacokinetic studies and in vitro binding assays used both female and male Friend leukemia virus strain B (FVB) wild-type and multidrug resistance protein $1 \mathrm{a} / \mathrm{b}\left(\mathrm{Mdr} 1 \mathrm{a} / \mathrm{b}^{--}\right)$and $\mathrm{Bcrp} 1^{-1-}$ mice (Taconic Biosciences, Inc., Germantown, NY) at the age of 8-14 weeks. Animals were bred and maintained in the accredited research animal housing facility at the University of Minnesota. Transgenic mouse colonies were routinely validated by conducting tail snip followed by genotyping (TransnetYX, Cordova, TN). All protocols for the animal experiments were approved by the University of Minnesota Institutional Animal Care and Use Committee and performed in accordance with the Guide for the Care and Use of Laboratory Animals by the US National Institutes of Health (Bethesda, MD).

Discrete-Dosing Pharmacokinetic Study. The dosing suspensions for subcutaneous injection were prepared in 10\% dimethylsulfoxide (DMSO) and $0.25 \%$ hydroxypropyl methylcellulose (w/v) to achieve a dose of $1 \mathrm{mg} / \mathrm{kg}$ for each EGFR inhibitor. A single dose of each EGFR inhibitor was individually dosed in wildtype and triple-knockout $\left(\right.$ Mdrla/ $\left.b^{-1} \mathrm{Bcrpl}^{-1}\right) \mathrm{FVB}$ mice. Blood and brain samples from mice were harvested at 1 and 8 hours after discrete drug administration ( $N=3$ to 4 at each time point). Blood was collected by cardiac puncture using heparinized syringes after euthanizing in a carbon dioxide chamber. Plasma was separated by centrifuge at $6500 \mathrm{rpm}$ at $4^{\circ} \mathrm{C}$ for 20 minutes. Both plasma and brain samples were stored at $-80^{\circ} \mathrm{C}$ until liquid chromatography-tandem mass spectrometry (LC-MS/MS) analysis.

Cassette-Dosing Pharmacokinetic Study. The dosing suspension for cassette dosing was prepared in the final strength of $10 \%$ DMSO and $0.25 \%$ hydroxypropyl methylcellulose (w/v) the same way as for discrete dosing to make the mixture of eight EGFR inhibitors in a final dosing suspension of $1 \mathrm{mg} / \mathrm{kg}$. A single cocktail of eight EGFR inhibitors was administered by subcutaneous injection in wild-type and triple-knockout $\left(M d r 1 a / b^{-1} B_{c r p 1^{--}}\right)$FVB mice. Blood and brain samples were harvested at predetermined time points, including $0.5,1$, $2,4,8$, and 16 hours after dosing ( $N=3$ to 4 at each time point). Blood and plasma were collected and separated as described in the discrete-dosing study.

Protein Binding Study in Plasma and Brain Homogenate. The free fractions of EGFR inhibitors were determined by using a rapid equilibrium dialysis device. Mouse plasma was obtained from FVB mice by cardiac puncture. The brain homogenate was prepared from FVB mouse by adding 2 volumes (w/v) of phosphate-buffered saline ( $\mathrm{pH}$ 7.4) followed by mechanical homogenization. EGFR inhibitor stock solutions were prepared in DMSO and added to either mouse plasma or brain homogenate to make a final concentration of $5 \mu \mathrm{M}$ containing 0.3\% DMSO. Either mouse plasma or brain homogenate containing compounds was loaded to the sample chamber $(300 \mu \mathrm{l})$ of the inserts first, and then blank phosphate-buffered saline was loaded to the corresponding buffer chamber $(500 \mu \mathrm{l})$ according to the manufacturer's instructions $(N=4)$. The plate was sealed with an adhesive lid and incubated at $37^{\circ} \mathrm{C}$ for 4 hours in an orbital shaker at $300 \mathrm{rpm}$. Samples were collected from both chambers after the incubation and stored in a $-80^{\circ} \mathrm{C}$ freezer until LC-MS/MS analysis. 
Unbound free fractions in the brain were calculated according to the following equation (Kalvass and Maurer, 2002):

$$
\text { free fraction }\left(\mathrm{f}_{\mathrm{u}}\right)=\frac{1 / \mathrm{D}}{\left(\left(\frac{1}{\mathrm{f}_{\mathrm{u} \text {,diluted }}}\right)-1\right)+1 / \mathrm{D}} \text {. }
$$

The dilution factor (D) was 3 in the previously described experiment.

The unbound (free) concentration partitioning to the brain was determined as follows:

$$
\begin{aligned}
\text { free brain partition coefficient }\left(\mathrm{K}_{\mathrm{p}, \mathrm{uu}}\right) & =\frac{\text { free brain concentration }}{\text { free plasma concentration }} \\
& =\mathrm{K}_{\mathrm{p}, \text { brain }} \times \frac{\mathrm{f}_{\mathrm{u}, \text { brain }}}{\mathrm{f}_{\mathrm{u}, \text { plasma }}}
\end{aligned}
$$

where $\mathrm{K}_{\mathrm{p} \text {,brain }}$ is the ratio of brain-to-plasma areas under the total concentrationtime profile as follows:

$$
\text { brain partition coefficient }\left(\mathrm{K}_{\mathrm{p}, \text { brain }}\right)=\frac{\mathrm{AUC}_{\mathrm{brain}}}{\mathrm{AUC}_{\mathrm{plasma}}}
$$

The distribution advantage (DA) due to the lack of efflux transporters was calculated as follows:

$$
\mathrm{DA}=\frac{\mathrm{K}_{\mathrm{p}, \text { brain }}, \text { transporter knockout mice }}{\mathrm{K}_{\mathrm{p}, \text { brain }}, \text { wild-type mice }}
$$

Analytical LC-MS/MS Analysis to Determine Drug Concentrations. Concentrations of the eight EGFR inhibitors in specimens were measured using reverse-phase liquid chromatography (Agilent model 1200 separation system; Agilent Technologies, Santa Clara, CA) coupled with a TSQ Quantum triple quadrupole mass spectrometer (Thermo Finnigan, San Jose, CA) by operating electrospray in the positive ion mode. For liquid chromatographic separation, either gradient or isocratic elution was performed using a Phenomenex Synergi Polar-RP column $(75 \times 2 \mathrm{~mm}, 4 \mu \mathrm{m}$; Phenomenex $)$ depending on the compounds. The initial composition of the mobile phase for AEE788, AZD3759, afatinib, and gefitinib was composed of $75 \%$ distilled water with $0.1 \%$ formic acid (A) and $25 \%$ acetonitrile with $0.1 \%$ formic acid (B) with a $0.35-\mathrm{ml} / \mathrm{min}$ flow rate. The total run time was 7.5 minutes. The retention times for AEE788, AZD3759, afatinib, and gefitinib were $1.01,1.30,1.00$, and 1.43 minutes, respectively. The initial mobile phase composition for osimertinib, erlotinib, and vandetanib was comprised of $70 \%$ distilled water with $0.1 \%$ formic acid (A) and $30 \%$ acetonitrile with $0.1 \%$ formic acid (B) with a $0.35-\mathrm{ml} / \mathrm{min}$ flow rate. The total run time was 8.5 minutes. The retention times for osimertinib, erlotinib, and vandetanib were 1.06, 3.54, and 0.73 minutes, respectively. An isocratic separation was performed to separate dacomitinib with the initial condition of $70 \%$ aqueous phase (A) and $30 \%$ organic phase (B) for 4 minutes. The retention time for dacomitinib was 0.85 minutes. Massto-charge ratio $(\mathrm{m} / \mathrm{z})$ transitions were as follows: $500.14>72.15$ for osimertinib, $504.14>72.14$ for $\left[{ }^{13} \mathrm{C},{ }^{2} \mathrm{H}_{3}\right]$-osimertinib, $460.1>141.16$ for AZD3759, $447.1>$ 128.2 for gefitinib, $455.1>136.2$ for $\left[{ }^{2} \mathrm{H}_{8}\right]$-gefitinib, $475.1>112.1$ for vandetanib, $481>112.1$ for $\left[{ }^{13} \mathrm{C},{ }^{2} \mathrm{H}_{6}\right]$-vandetanib, $394.1>278$ for erlotinib, $400.1>284$ for $\left[{ }^{2} \mathrm{H}_{6}\right]$-erlotinib, $486.1>371.1$ for afatinib, $492.1>377.1$ for $\left[{ }^{2} \mathrm{H}_{6}\right]$-afatinib, $441.27>223.05$ for AEE788, and 470.2 > 385.0 for dacomitinib.

Pharmacokinetic Calculations. Plasma and brain concentration-time data were analyzed with noncompartmental analysis (NCA) using Phoenix WinNonlin version 8.0 (Certara USA, Inc., Princeton, NJ). AUCs for each compound were calculated by the trapezoidal rule to the last time point $\left[\mathrm{AUC}_{(0 \rightarrow \text { tlast }}\right]$. Other pharmacokinetic parameters/metrics, including clearance, volume of distribution $\left(\mathrm{V}_{\mathrm{d}}\right)$, and half-life were determined by NCA. Brain-to-plasma ratios $\left(\mathrm{K}_{\mathrm{p}}\right)$ of each EGFR inhibitor were calculated by the ratio of $\mathrm{AUC}_{(0 \rightarrow \text { tlast })}$ of the brain concentration-time profile $\left[\mathrm{AUC}_{(0 \rightarrow \text { tlast }) \text {,brain }}\right]$ to that of the plasma concentrationtime profile $\left[\mathrm{AUC}_{(0 \rightarrow \text { tlast }) \text {,plasma }}\right]$. Free partition coefficients of brain $\left(\mathrm{K}_{\mathrm{p}, \mathrm{uu}}\right)$ were calculated by multiplying the $\mathrm{K}_{\mathrm{p}}$ with the ratio of free fraction in brain homogenate to plasma $\left(\mathrm{f}_{\mathrm{u}, \text { brain }} / \mathrm{f}_{\mathrm{u} \text {,plasma }}\right)$. A brain DA in triple-knockout mice, which were lacking both P-gp and Bcrp $\left(M d r l a / b^{-1} \mathrm{Bcrpl}^{-/-}\right)$, compared with wild-type mice was obtained by calculating the ratio of $\mathrm{K}_{\mathrm{p}}$ in triple-knockout to wild-type mice.

Statistical Testing. All data are presented as the mean \pm S.D. or standard error of an estimate (S.E.). To compare the brain-to-plasma ratio in cassette dosing to that in discrete dosing, a pairwise multiple $t$ test was performed by using GraphPad Prism (version 6; GraphPad Software, La Jolla, CA). A significance level at $P<0.05$ was considered as a statistically significant difference in all statistical testing.

\section{Results}

Comparison of Brain-to-Plasma Ratios from Cassette- and Discrete-Dosing Studies. The brain-to-plasma ratios of each drug at a 1 and 8 hours following cassette-dosing studies were compared with the results from discrete-dosing studies at the same times post dose in both wild-type and triple-knockout (TKO) mice (Fig. 2). Figure 2A shows that the brain-to-plasma ratios of the eight EGFR inhibitors from cassette dosing were within 2-fold of the ratios from discrete dosing in wild-type mice at 1 hour after dosing, except AEE788, which showed a higher brain-to-plasma ratio following discrete dosing than in cassette dosing $(P<0.05)$. Likewise, at 8 hours after dosing in wild-type mice, five out of seven compounds were within 2-fold difference in the cassette-dosing study when compared with the discrete-dosing study (Fig. 2B). The two exceptions, afatinib and osimertinib, showed a slightly higher brain-toplasma ratio in the cassette-dosing study than in the discrete-dosing study (afatinib: $P<0.05$; osimertinib: not significant). In TKO mice, brain-to-plasma ratios of these drugs from the cassette-dosing study matched well with the results from the discrete-dosing study, except AEE788 at 8 hours post dose (Fig. 2, C and D, $P<0.05$ ). Overall, the results from the cassette-dosing study show good agreement with those from discrete-dosing studies. Even though there were some values that were out of the 2-fold range, the brain-to-plasma ratios from cassetteand discrete-dosing strategies were comparable and support the use of the cassette dosing as a valid strategy to compare brain partition coefficients across the series of compounds.

Pharmacokinetic Parameters and Metrics of Eight EGFR Inhibitors following Cassette Dosing in Wild-Type and $\mathrm{Mdrla} / \mathrm{B}^{-/} \mathrm{Bcrp1}^{-/}$ FVB Mice. The concentration-time profiles of eight EGFR inhibitors following a single cassette dosing by subcutaneous injection were used to calculate pharmacokinetic parameters and metrics by using NCA in wild-type (WT) and TKO mice (Tables 2 and 3). The half-lives of inhibitors in plasma were calculated based on the concentrations of plasma at the last three or four time points in the concentration-time profile where the drugs were in the elimination phase. The half-lives of these drug ranged from 50 minutes with erlotinib to 13.7 hours with vandetanib in wild-type FVB mice, and from 50 minutes with erlotinib to 17.6 hours with AEE788 in triple-knockout (Mdr1a/b-/-Bcrp1-/-) FVB mice. When the half-life of each drug in wild-type FVB mice was compared with the values in knockout animals, seven out of eight inhibitors showed similar values within a 2-fold difference. Vandetanib showed differences over 2-fold in TKO FVB mice (5.74) when compared with wild-type mice (13.7), and the AUC in wild-type FVB mice was significantly higher than that in TKO mice [2230 \pm 61.3 (WT) vs. $1442 \pm 98.7$ (TKO), $P<0.05$ ]. Based on the noncompartmental analysis for vandetanib, the apparent volume of distribution $\left(\mathrm{V}_{\mathrm{d}} / \mathrm{F}\right)$ in WT was comparable to TKO [4947 ml/kg (WT) vs. $5085 \mathrm{ml} / \mathrm{kg}$ (TKO)], but the apparent clearance in TKO was about 2.5 -fold higher than the value in WT [250 ml/h/kg (WT) vs. $614 \mathrm{ml} / \mathrm{h} / \mathrm{kg}$ (TKO)]. Except for vandetanib, all other inhibitors showed similar plasma AUCs in wildtype when compared with TKO mice. Overall, half-lives of these inhibitors in the brain were close to the half-lives observed in plasma. Gefitinib and afatinib in wild-type mice and vandetanib in TKO were the exceptions that showed longer half-lives in brain than in plasma. Overall, systemic pharmacokinetic parameters and metrics in WT were similar to the values in TKO, but the AUCs in brain were markedly different in WT and TKO across all compounds following cassette dosing of a set of 
A Wild-type FVB mice at 1-hour post dose

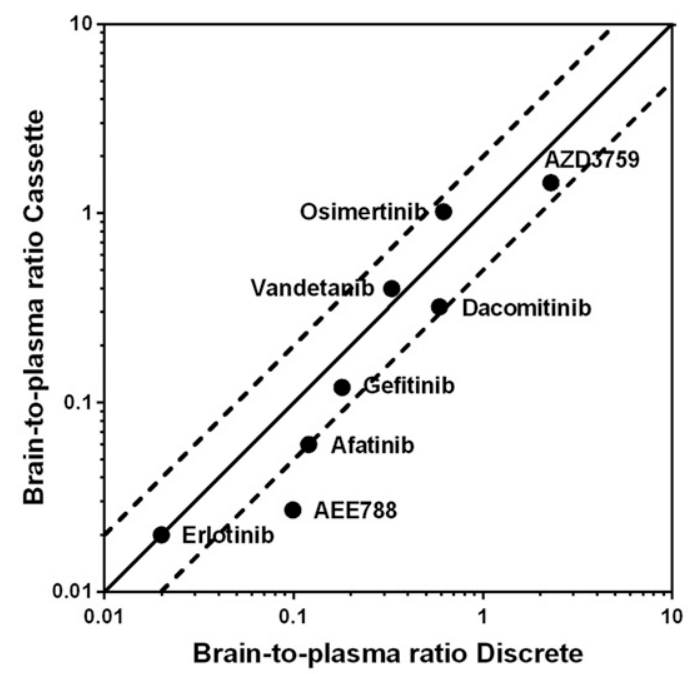

C Mdr1a/1 $\mathrm{b}^{-/-}$Bcrp1 $^{-/-}$FVB mice at 1-hour post dose

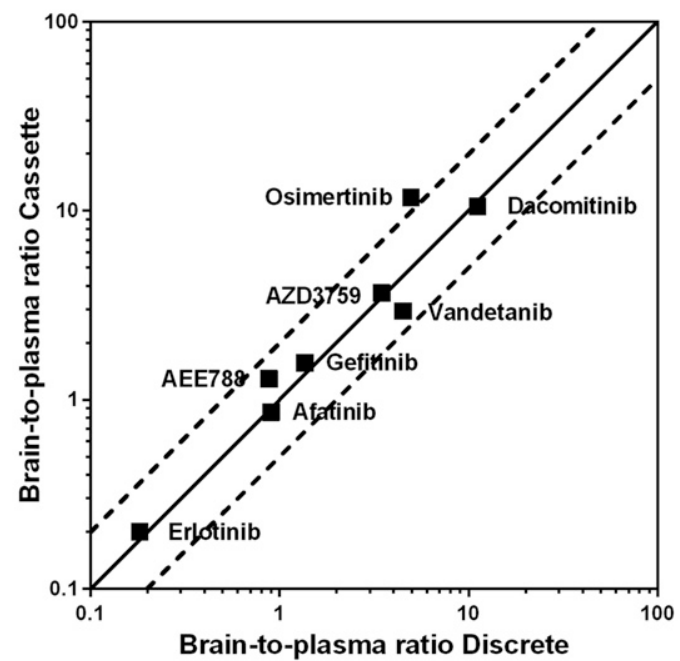

B Wild-type FVB mice at 8-hour post dose

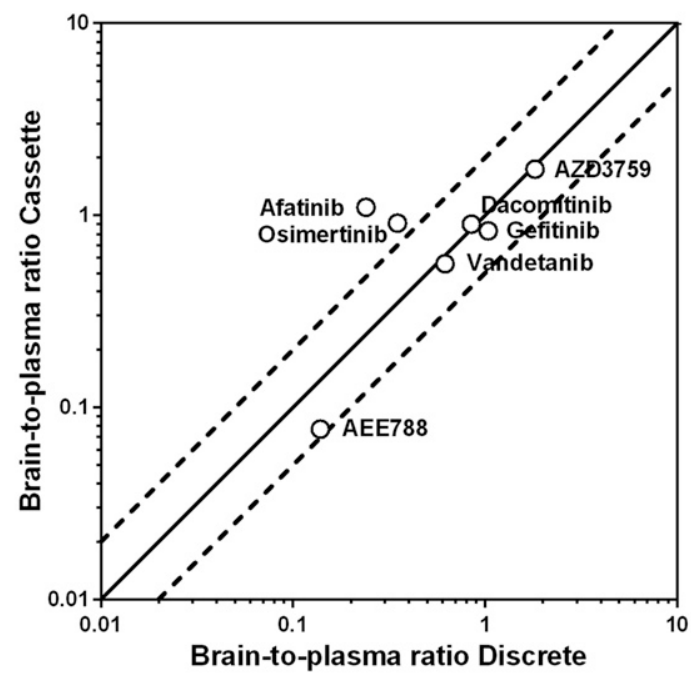

D Mdr1a/1 $\mathrm{b}^{-/-} \mathrm{Bcrp}^{-/-}$FVB mice at 8-hour post dose

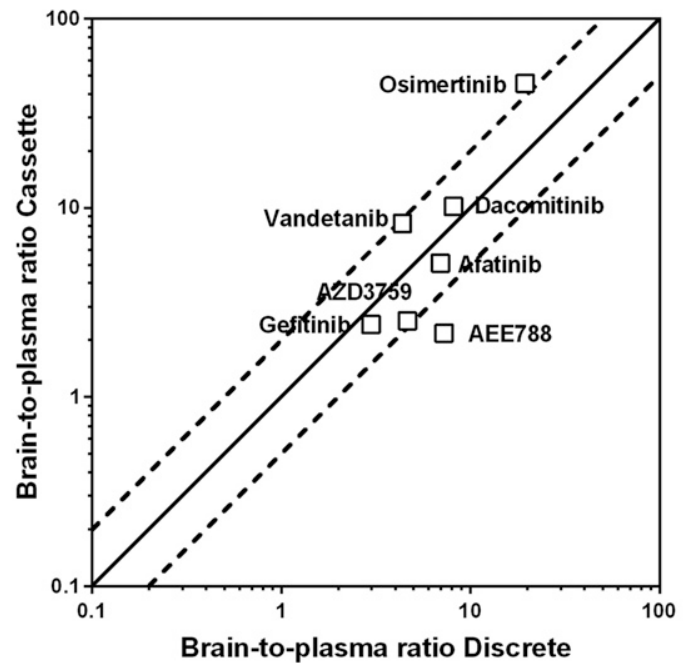

Fig. 2. Comparison of brain-to-plasma ratios between cassette and discrete dosing in wild-type and triple-knockout (Mdr1a/b ${ }^{-1-} \mathrm{Bcrp}^{-1-}$ ) FVB mice. (A) Brain-to-plasma ratios at 1 hour post dose in wild-type FVB mice. (B) Brain-to-plasma ratios at 8 hours post dose in wild-type FVB mice. (C) Brain-to-plasma ratios at 1 hour post dose in triple-knockout (Mdrla/b ${ }^{-1-} \mathrm{Bcrp}^{---}$) FVB mice. (D) Brain-to-plasma ratios at 8 hour post dose in Mdrla/b ${ }^{-1-} \mathrm{Bcrp}^{-1-}$ FVB mice.

EGFR inhibitors (concentration-time profiles of each drug are available in Supplemental Figs. 1 and 2).

Brain Penetration of EGFR Inhibitors within an Individual Animal. The brain penetration of each EGFR inhibitor following cassette dosing was examined by calculating the brain-to-plasma ratio of each compound at each time point within individual animal subjects. This allowed these compounds to be rank ordered from the highest penetration (high brain-to-plasma ratio) to the lowest penetration (low brain-to-plasma ratio) within a single animal subject. Ranked values within the same subjects were color coded, depending on their brain penetration, in Fig. 3, where dark blue was used for a compound with the highest brain penetration, and dark red was used for the drugs with the lowest brain penetration. When the measured concentration was lower than the lowest limit of quantitation, the "penetration" color was grayed and marked as LLOQ. This "visual heat map" of the rank order of the brain penetration of inhibitors was consistent across different subjects at different time points in both wild-type and triple-knockout mice. The overall classification of brain penetration, defined with color, either in the blue group or the red group, was consistent, especially at the same time point after dosing. Interestingly, these rank orders within a mouse are more consistent across mice at early time points until approximately 2 hours after cassette dosing, and less consistent at later time points in both WT and TKO animals.

Determination of $\mathbf{K}_{\mathbf{p}}$ and $\mathbf{K}_{\mathbf{p}, \mathbf{u u}}$ for Brain. The partition coefficients $\left(\mathrm{K}_{\mathrm{p}}\right)$ of brain for this set of EGFR inhibitors were determined in both wild-type and TKO FVB mice from the cassette-dosing study (Supplemental Fig. 3; Table 4). The brain partition coefficients were calculated by the ratios of AUC of brain total concentration-time profile to AUC of plasma concentration-time profile from time zero to the last time point of measured concentrations (16 hours). In wild-type mice that had intact efflux transporters in the BBB, the brain $\mathrm{K}_{\mathrm{p}}$ was the highest for AZD3759 (1.7) and lowest for erlotinib and AEE788 (0.062 and 0.066, respectively). These $K_{p}$ values were increased in TKO mice for all studied compounds when compared with wild-type mice. However, the relative magnitude of increase in $\mathrm{K}_{\mathrm{p}}$ was highly variable, from 1.6-fold for AZD3759 up to 28-fold for AEE788, as quantified by DA with eq. 4, 
TABLE 2

Pharmacokinetic parameters in wild-type mice

The values were larger than the half-life in plasma because the complete elimination phase was not captured in the experiments.

\begin{tabular}{|c|c|c|c|c|c|c|c|c|c|}
\hline & Unit & AEE788 & Afatinib & AZD3759 & Dacomitinib & Erlotinib & Gefitinib & Osimertinib & Vandetanib \\
\hline$t_{\text {half }}$ & $\mathrm{h}$ & 12.4 & 7.20 & 2.37 & 8.45 & 0.827 & 2.66 & 2.77 & 13.7 \\
\hline Apparent CL & $\mathrm{ml} / \mathrm{h} / \mathrm{kg}$ & 582 & 1196 & 1915 & 881 & 961 & 1706 & 1407 & 250 \\
\hline Apparent $\mathrm{V}_{\mathrm{d}}$ & $\mathrm{ml} / \mathrm{kg}$ & 10,377 & 12,389 & 6539 & 10,723 & 1146 & 6542 & 5632 & 4947 \\
\hline$t_{\text {half, brain }}$ & $\mathrm{h}$ & 13.9 & $25.7^{a}$ & 2.69 & 10.5 & 0.75 & $14.2^{a}$ & 2.27 & 10.6 \\
\hline $\mathrm{AUC}_{\text {last, plasma }}$ & $\mathrm{h} * \mathrm{ng} / \mathrm{ml}$ & 985 & 734 & 486 & 826 & 1001 & 576 & 645 & 2230 \\
\hline S.E._AUC last, plasma & $\mathrm{h} * \mathrm{ng} / \mathrm{ml}$ & 23.3 & 80.6 & 27.7 & 79.2 & 39.6 & 54.6 & 43.7 & 61.3 \\
\hline $\mathrm{AUC}_{\text {last, brain }}$ & $\mathrm{h}^{*} \mathrm{ng} / \mathrm{ml}$ & 65.3 & 186 & 828 & 505 & 62.4 & 206 & 638 & 1416 \\
\hline S.E._AUC last, brain & $\mathrm{h} * \mathrm{ng} / \mathrm{ml}$ & 2.20 & 3.35 & 60.8 & 24.0 & 8.21 & 3.85 & 31.9 & 95.0 \\
\hline
\end{tabular}

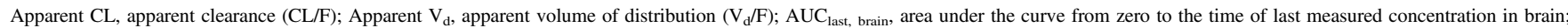

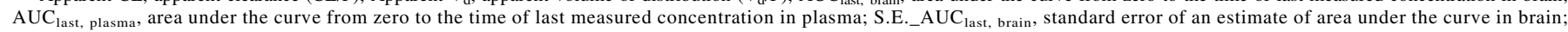
S.E._AUC ${ }_{\text {last, plasma, }}$ standard error of an estimate of area under the curve in plasma; $t_{\text {half }}$, half-life of a drug in plasma; $t_{\text {half, brain }}$, half-life of a drug in brain.

${ }^{a}$ The half-life was determined by the slope of last three time points in concentration-time profile.

as shown in Table 4. The free fractions of these compounds were determined in mouse plasma and brain homogenate using rapid equilibrium dialysis. The free partition coefficients of brain $\left(\mathrm{K}_{\mathrm{p}, \mathrm{uu}}\right)$ are presented in Table $4 . K_{p}$ and $K_{p \text {,uu }}$ values were highest with AZD3759 in wild-type mice. $K_{p}$ was lowest with erlotinib in wild-type mice, whereas $\mathrm{K}_{\mathrm{p} \text {,uu }}$ was lowest with AEE788 in wild-type mice. Importantly, in the wild-type mice, most of the $K_{p \text {,uu }}$ values were well below unity, indicating that the efflux system(s) plays a significant role in limiting the brain penetration of these EGFR inhibitors. AZD3759 was the only compound that showed a $K_{p, u u}$ higher than unity (i.e., 2.96), indicative of a possible involvement of an influx system on modulating the delivery of this compound across the BBB. The rank orders of $K_{p}$ and $K_{p}$,uu values showed that osimertinib had the highest $\mathrm{K}_{\mathrm{p}}$ in TKO mice (15.7), which is about 16-fold higher than in wild-type mice. Although the rank orders of these values changed depending on not only the degree of binding in plasma and brain but also the presence and absence of efflux transporters, AZD3759, osimertinib, vandetanib, and dacomitinib consistently ranked with a comparatively high brain penetration. On the other hand, the other four compounds in this cassette of eight EGFR inhibitors (erlotinib, AEE788, afatinib, and gefitinib) were categorized in the low brain penetration group.

Correlation between Physicochemical Properties and the Brain Partition Coefficients. Correlations between physicochemical properties and the brain penetration of this set of EGFR inhibitors were examined. A calculated CNS MPO score (Wager et al., 2010) and the ratios of clog D to square root of molecular weight [clog D/sqrt(MW)] (Levin, 1980) were compared with $\mathrm{K}_{\mathrm{p} \text {,brain }}$ and $\mathrm{K}_{\mathrm{p} \text {,uu }}$ in wild-type and TKO mice (Fig. 4; Table 5). The suggested CNS MPO scores are typically higher than 4 to predict good CNS penetration (Wager et al., 2016), and the MPO scores for the series of EGFR inhibitors were calculated by the most recent version of MPO score calculation tool (Wager et al., 2016). Importantly, using this tool, dacomitinib, vandetanib, and osimertinib were classified as low brain penetrants according to their MPO scores, but erlotinib and gefitinib were classified as high brain penetrants. On the other hand, the method of predicting brain penetration of compounds by using the ratios of $\operatorname{clog} \mathrm{D}$ to the square root of molecular weight predicted dacomitinib, vandetanib, and AEE788 as high brain penetrants and erlotinib as a low brain penetrant. Based on the experimentally determined brain partition coefficients $\left(\mathrm{K}_{\mathrm{p}}\right)$ reported earlier from our cassette-dosing studies, osimertinib, dacomitinib, and vandetanib were consistently classified as high brain penetrants in wild-type FVB mice, and erlotinib and gefitinib were classified as low brain penetrants. Moreover, compounds with similar MPO scores, such as AEE788 (3.3) and vandetanib (3.3), had widely different $K_{p}$ values in wild-type mice, ranging from 0.635 for vandetanib, classified as highly brain penetrant, to 0.066 for AEE788, classified as a low brain penetrant (Fig. 4C; Table 5). A similar pattern was observed with clog D/sqrt(MW) in AEE788, dacomitinib, and erlotinib, where each had close clog D/sqrt(MW) values but $\mathrm{K}_{\mathrm{p}}$ values that were considerably different from one another. The free partition coefficients of brain $\left(K_{p, u u}\right)$ were plotted against either clog D/sqrt(MW) or MPO scores to understand the influence of binding in these correlations; however, no improved correlation was seen in these parameters (Fig. 4). When the effect of major transporters, P-gp and Bcrp, was absent using TKO mice, the $\mathrm{K}_{\mathrm{p} \text {,brain }}$ seemed to have a modest correlation with clog D/sqrt(MW) but no correlation with MPO scores

TABLE 3

Pharmacokinetic parameters in TKO mice

The values were larger than the half-life in plasma because complete elimination phase was not captured in the experiments.

\begin{tabular}{|c|c|c|c|c|c|c|c|c|c|}
\hline & Unit & AEE788 & Afatinib & AZD3759 & Dacomitinib & Erlotinib & Gefitinib & Osimertinib & Vandetanib \\
\hline$t_{\text {half }}$ & $\mathrm{h}$ & 17.6 & 5.95 & 2.75 & 8.99 & 0.846 & 4.20 & 2.24 & 5.74 \\
\hline Apparent CL & $\mathrm{ml} / \mathrm{h} / \mathrm{kg}$ & 531 & 679 & 1598 & 822 & 1570 & 1431 & 1657 & 614 \\
\hline Apparent $\mathrm{V}_{\mathrm{d}}$ & $\mathrm{ml} / \mathrm{kg}$ & 13,502 & 5827 & 6349 & 10,667 & 1916 & 8680 & 5353 & 5085 \\
\hline$t_{\text {half, brain }}$ & $\mathrm{h}$ & 5.1 & 10.5 & 2.32 & 16.6 & 0.95 & 4.76 & 3.59 & $41.8^{a}$ \\
\hline AUC $_{\text {last, plasma }}$ & $\mathrm{h} * \mathrm{ng} / \mathrm{ml}$ & 858 & 1279 & 617 & 877 & 609 & 658 & 566 & 1442 \\
\hline S.E._AUC last, plasma & $\mathrm{h}^{*} \mathrm{ng} / \mathrm{ml}$ & 61.8 & 234 & 95.9 & 135 & 49.7 & 95.3 & 81.6 & 98.7 \\
\hline $\mathrm{AUC}_{\text {last, brain }}$ & $\mathrm{h}^{*} \mathrm{ng} / \mathrm{ml}$ & 1599 & 3082 & 1633 & 8572 & 124 & 1449 & 8913 & 10,773 \\
\hline S.E._AUC ${ }_{\text {last, brain }}$ & $\mathrm{h}^{*} \mathrm{ng} / \mathrm{ml}$ & 89.1 & 174 & 72.0 & 307 & 6.12 & 57.0 & 1584 & 563 \\
\hline
\end{tabular}

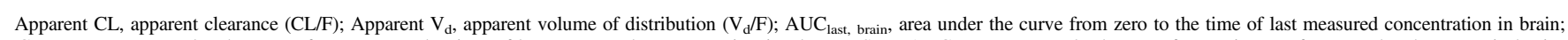

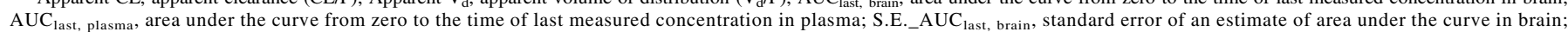

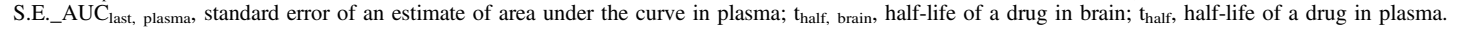

${ }^{a}$ The half-life was determined by the slope of last three time points in concentration-time profile. 
A

Rank order in wild-type (WT) mice

\begin{tabular}{|c|c|c|c|c|c|c|c|c|c|}
\hline Animal ID & $\begin{array}{c}\text { Time of } \\
\text { Collection }\end{array}$ & Erlotinib & AEE788 & Afatinib & Gefitinib & Dacomitinib & Vandetanib & Osimertinib & AZD3759 \\
\hline 1 & $0.5 \mathrm{~h}$ & 0.031 & 0.030 & 0.121 & 0.135 & 0.491 & 0.302 & 0.789 & 0.357 \\
\hline 2 & $0.5 \mathrm{~h}$ & 0.027 & 0.061 & 0.038 & 0.130 & 0.266 & 0.424 & 0.566 & 1.97 \\
\hline 3 & $0.5 \mathrm{~h}$ & 0.029 & 0.031 & 0.070 & 0.119 & 0.174 & 0.302 & 0.716 & 1.67 \\
\hline 4 & $0.5 \mathrm{~h}$ & 0.027 & 0.031 & 0.032 & 0.115 & 0.209 & 0.295 & 0.239 & 1.48 \\
\hline 5 & $1 \mathrm{~h}$ & 0.016 & 0.021 & 0.022 & 0.071 & 0.399 & 0.355 & 0.597 & 1.09 \\
\hline 6 & $1 \mathrm{~h}$ & 0.022 & 0.028 & 0.059 & 0.129 & 0.494 & 0.333 & 1.06 & 1.32 \\
\hline 7 & $1 \mathrm{~h}$ & 0.028 & 0.044 & 0.070 & 0.167 & 0.243 & 0.607 & 1.44 & 2.04 \\
\hline 8 & $1 \mathrm{~h}$ & 0.018 & 0.016 & 0.044 & 0.104 & 0.139 & 0.314 & 1.00 & 1.35 \\
\hline 9 & $2 \mathrm{~h}$ & 0.015 & 0.060 & 0.147 & 0.166 & 1.76 & 0.347 & 1.59 & 1.45 \\
\hline 10 & $2 \mathrm{~h}$ & 0.028 & 0.094 & 0.207 & 0.216 & 1.43 & 0.337 & 1.73 & 1.53 \\
\hline 11 & $2 \mathrm{~h}$ & 0.018 & 0.046 & 0.055 & 0.104 & ND & 0.739 & 1.23 & 1.77 \\
\hline 12 & $2 \mathrm{~h}$ & 0.017 & 0.046 & 0.078 & 0.128 & ND & 0.494 & 0.950 & 1.08 \\
\hline 13 & $4 \mathrm{~h}$ & 0.020 & 0.084 & 0.165 & 0.229 & 0.593 & 0.816 & 1.95 & 1.37 \\
\hline 14 & $4 \mathrm{~h}$ & 0.027 & 0.092 & 0.417 & 0.195 & 0.359 & 0.570 & 1.80 & 1.97 \\
\hline 15 & $4 \mathrm{~h}$ & 2.68 & 0.084 & 0.483 & 0.359 & 0.435 & 1.34 & 1.44 & 1.95 \\
\hline 16 & $4 \mathrm{~h}$ & LLOQ & 0.098 & 0.481 & 0.658 & 0.623 & 1.16 & 1.14 & 2.00 \\
\hline 17 & $8 \mathrm{~h}$ & LLOQ & 0.074 & 1.03 & LLOQ & 1.12 & 0.538 & 0.485 & 2.32 \\
\hline 18 & $8 \mathrm{~h}$ & LLOQ & 0.081 & 0.970 & 1.30 & 1.17 & 0.509 & 0.798 & 1.94 \\
\hline 19 & $8 \mathrm{~h}$ & LLOQ & 0.070 & 1.07 & 0.677 & 0.361 & 0.606 & 1.25 & 1.54 \\
\hline 20 & $8 \mathrm{~h}$ & LLOQ & 0.082 & 1.32 & 0.498 & 0.946 & 0.588 & 1.10 & 1.15 \\
\hline 21 & $16 \mathrm{~h}$ & LLOQ & 0.073 & 1.11 & LLOQ & LLOQ & 0.571 & 0.159 & 5.45 \\
\hline 22 & $16 \mathrm{~h}$ & LLOQ & 0.071 & LLOQ & 3.78 & 1.01 & LLOQ & LLOQ & LLOQ \\
\hline 23 & $16 \mathrm{~h}$ & LLOQ & 0.084 & 1.08 & 3.97 & 0.586 & 0.732 & 0.050 & 2.17 \\
\hline 24 & $16 \mathrm{~h}$ & LLOQ & 0.077 & 1.34 & 2.47 & 0.193 & 0.793 & 0.104 & 21.2 \\
\hline
\end{tabular}

\section{B}

Rank order in Mdr1a/b ${ }^{-/-} \mathrm{Bcrp1}^{-/-}$(Triple knockout, TKO) mice

\begin{tabular}{|c|c|c|c|c|c|c|c|c|c|}
\hline Animal ID & $\begin{array}{l}\text { Time of } \\
\text { Collection }\end{array}$ & Erlotinib & Afatinib & AEE788 & Gefitinib & AZD3759 & Vandetanib & Dacomitinib & Osimertinib \\
\hline 1 & $0.5 \mathrm{~h}$ & 0.423 & 0.562 & 1.85 & 0.897 & 1.33 & 1.74 & 3.09 & 5.71 \\
\hline 2 & $0.5 \mathrm{~h}$ & 0.167 & 0.468 & 0.574 & 1.00 & 2.90 & 1.64 & 4.05 & 5.84 \\
\hline 3 & $0.5 \mathrm{~h}$ & 0.159 & 0.193 & 0.658 & 0.661 & 2.18 & 2.45 & 14.2 & 8.27 \\
\hline 4 & $0.5 \mathrm{~h}$ & 0.131 & 0.583 & 0.621 & 0.92 & 2.97 & 1.81 & 11.3 & 3.06 \\
\hline 5 & $1 \mathrm{~h}$ & 0.258 & 1.14 & 1.21 & 1.39 & 3.10 & 3.70 & ND & 17.7 \\
\hline 6 & $1 \mathrm{~h}$ & 0.179 & 1.15 & 1.08 & 1.38 & 3.04 & 2.72 & 5.88 & 5.55 \\
\hline 7 & $1 \mathrm{~h}$ & 0.217 & 0.272 & 1.43 & 2.01 & 5.94 & 3.03 & 4.19 & 20.0 \\
\hline 8 & $1 \mathrm{~h}$ & 0.147 & 0.875 & 1.45 & 1.50 & 2.59 & 2.37 & 21.6 & 3.67 \\
\hline 9 & $2 \mathrm{~h}$ & 0.354 & 1.94 & 2.63 & 2.52 & 4.39 & 3.10 & 12.4 & 7.66 \\
\hline 10 & $2 \mathrm{~h}$ & 0.164 & 1.10 & 4.65 & 4.73 & 5.66 & 7.15 & 16.4 & 23.1 \\
\hline 11 & $2 \mathrm{~h}$ & 0.278 & 1.86 & 1.53 & 1.49 & 2.45 & 4.66 & 10.5 & 3.58 \\
\hline 12 & $2 \mathrm{~h}$ & 0.201 & 1.16 & 0.943 & 1.33 & 2.11 & 4.57 & 4.93 & 20.0 \\
\hline 13 & $4 \mathrm{~h}$ & 4.18 & 3.11 & 2.69 & 2.39 & 2.66 & 8.01 & 24.1 & 52.3 \\
\hline 14 & $4 \mathrm{~h}$ & 0.150 & 3.43 & 4.20 & 2.77 & 2.43 & 8.29 & 19.3 & 19.9 \\
\hline 15 & $4 \mathrm{~h}$ & 0.057 & 2.55 & 3.42 & 3.25 & 3.48 & 5.83 & 23.7 & 16.3 \\
\hline 16 & $4 \mathrm{~h}$ & 0.915 & 7.97 & 2.20 & 6.65 & 19.2 & 7.19 & 17.1 & 10.3 \\
\hline 17 & $8 \mathrm{~h}$ & LLOQ & 0.944 & 1.22 & 0.96 & 0.42 & 13.5 & 18.5 & LLOQ \\
\hline 18 & $8 \mathrm{~h}$ & LLOQ & 2.11 & 1.99 & 2.22 & 2.28 & 6.04 & 11.3 & 46.7 \\
\hline 19 & $8 \mathrm{~h}$ & LLOQ & 6.71 & 3.07 & 3.30 & 2.65 & 41.8 & 28.2 & 64.5 \\
\hline 20 & $8 \mathrm{~h}$ & LLOQ & 6.51 & 2.46 & 3.22 & 2.67 & 5.30 & 12.0 & 25.3 \\
\hline 21 & $16 \mathrm{~h}$ & LLOQ & 3.21 & 0.773 & 2.23 & 0.766 & 23.3 & 6.24 & 5.18 \\
\hline 22 & $16 \mathrm{~h}$ & LLOQ & 6.41 & 0.921 & 3.69 & 11.4 & LLOQ & LLOQ & LLOQ \\
\hline 23 & $16 \mathrm{~h}$ & LLOQ & 8.59 & 0.713 & 11.3 & LLOQ & LLOQ & LLOQ & LLOQ \\
\hline
\end{tabular}

Fig. 3. Rank order of the brain distribution of EGFR inhibitors in a single animal. Rank order was based on the brain-to-plasma ratio at a single time point after dosing in individual animal. A. Rank order of brain to plasma ratios in wild-type mice, B. Rank order of brain to plasma ratios in Mdrla/b $\mathrm{b}^{-1} \mathrm{Bcrp}^{-1}{ }^{-}$(triple knockout) mice LLOQ, lowest limit of quantitation; ND, not determined. 
TABLE 4

The partition coefficients and free partition coefficients of brain for EGFR inhibitors

\begin{tabular}{|c|c|c|c|c|c|c|c|c|}
\hline & AEE788 & Afatinib & AZD3759 & Dacomitinib & Erlotinib & Gefitinib & Osimertinib & Vandetanib \\
\hline $\mathrm{K}_{\mathrm{p} \text { brain, wild type }}$ & 0.066 & 0.254 & 1.70 & 0.612 & 0.062 & 0.358 & 0.988 & 0.635 \\
\hline $\mathrm{K}_{\mathrm{p} \text {,brain }}, \mathrm{TKO}$ & 1.86 & 2.41 & 2.65 & 9.77 & 0.204 & 2.20 & 15.7 & 7.47 \\
\hline $\mathrm{f}_{\mathrm{u}, \mathrm{p}}$ & 0.068 & 0.080 & 0.058 & 0.008 & 0.045 & 0.041 & 0.005 & 0.055 \\
\hline $\mathrm{f}_{\mathrm{u}, \mathrm{b}}$ & 0.029 & 0.014 & 0.101 & 0.007 & 0.096 & 0.012 & 0.001 & 0.012 \\
\hline $\mathrm{K}_{\mathrm{p}, \mathrm{uu}}$, wild-type & 0.029 & 0.046 & 2.96 & 0.493 & 0.134 & 0.103 & 0.289 & 0.138 \\
\hline $\mathrm{K}_{\mathrm{p}, \mathrm{uu}}, \mathrm{TKO}$ & 0.804 & 0.433 & 4.61 & 7.88 & 0.438 & 0.631 & 4.61 & 2.65 \\
\hline DA & 28.1 & 9.49 & 1.56 & 16.0 & 3.27 & 6.16 & 15.9 & 19.1 \\
\hline
\end{tabular}

DA, distribution advantage calculated by the ratios of $\mathrm{K}_{\mathrm{p} \text { brain }}$ in transgenic to $\mathrm{K}_{\mathrm{p} \text { brain }}$ in wild type; $\mathrm{f}_{\mathrm{u}, \mathrm{b}}$, free fraction in brain homogenate measured by rapid equilibrium dialysis $(n=4)$; $\mathrm{f}_{\mathrm{up}}$, free

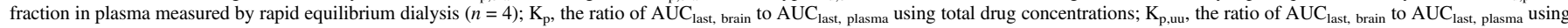
free drug concentrations.

(Fig. 4, B and D). In conclusion, both clog D/sqrt(MW) and MPO score failed to show a clear predictive correlation with either $\mathrm{K}_{\mathrm{p} \text {,brain }}$ or $\mathrm{K}_{\mathrm{p} \text {,uu,brain. }}$ About half of the compounds showed a weak correlation between their physicochemical properties and brain distribution, whereas the other half showed no correlation.

\section{Discussion}

EGFR has been an attractive target for treatment of primary brain tumors, including glioblastoma, in which EGFR is overexpressed in about 60\% of patients (Ohgaki and Kleihues, 2007; Huang et al., 2009; Brennan et al., 2013), as well as brain metastases from various cancers.
However, one of the major challenges in developing an efficacious anticancer drug for tumors located in the brain is "delivery" of these agents to the site of action, the brain tumor across an often intact BBB. A brain-to-blood partition coefficient $\left(\mathrm{K}_{\mathrm{p} \text {,brain }}\right)$ is commonly used to experimentally determine and describe the brain distribution of a drug, requiring animal experiments. Recently, other methods, including a cassette-dosing strategy ( $N$-in- 1 dosing), as well as prediction methods based on various physicochemical properties of a compound have been suggested to determine or predict the brain distribution of therapeutics, which can possibly replace the experimental processes, especially in discovery and development of brain penetrant compounds. The present study shows that the cassette-dosing approach can be useful to determine
A

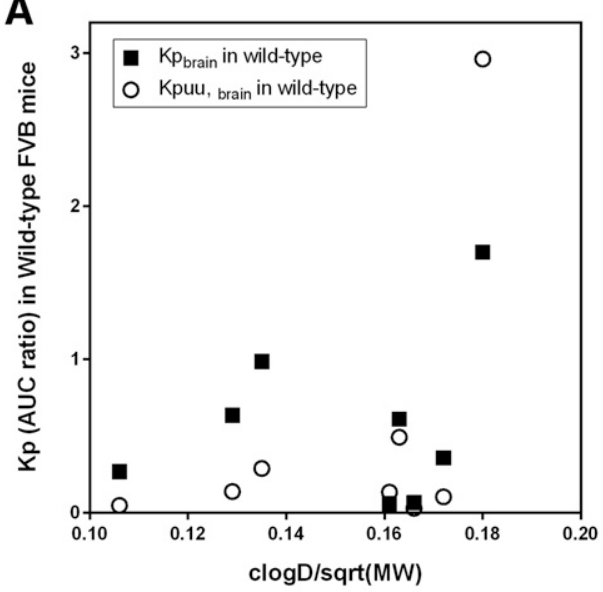

C

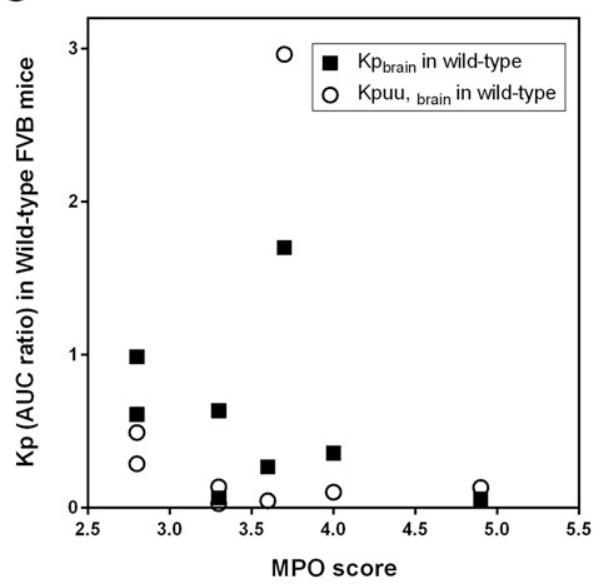

B

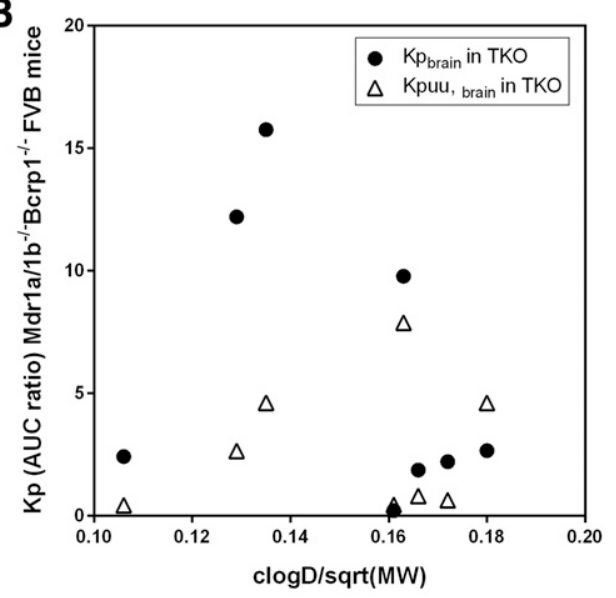

D

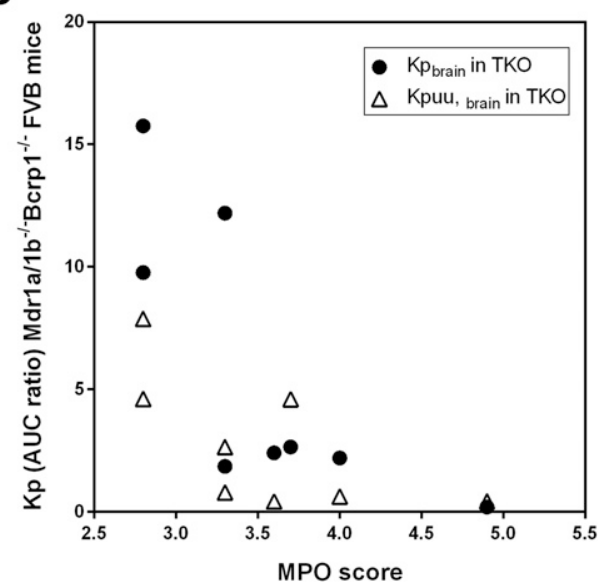

Fig. 4. Correlation between $K_{p}$ and clog $\mathrm{D} / \mathrm{sqrt}(\mathrm{MW})$ or MPO scores. (A) Correlation between $\mathrm{K}_{\mathrm{p}}$ or $\mathrm{K}_{\mathrm{p} \text {,uu }}$ in wild-type FVB mice and clog $\mathrm{D} / \mathrm{sqrt}(\mathrm{MW})\left(R^{2}\right.$ for $\mathrm{K}_{\mathrm{p}}=$ $0.04895, R^{2}$ for $\mathrm{K}_{\mathrm{p} \text {,uu }}=0.224$ ). (B) Correlation between $\mathrm{K}_{\mathrm{p}}$ or $\mathrm{K}_{\mathrm{p}, \mathrm{uu}}$ in triple-knockout $\left(\mathrm{Mdr} 1 \mathrm{a} / \mathrm{b}^{-1-} \mathrm{Bcrp}^{-1-}\right)$ FVB mice and clog $\mathrm{D} / \mathrm{sqrt}(\mathrm{MW})\left(R^{2}\right.$ for $\mathrm{K}_{\mathrm{p}}=0.137, R^{2}$ for $\mathrm{K}_{\mathrm{p} \text {,uu }}=$ 0.0386). (C) Correlation between $\mathrm{K}_{\mathrm{p}}$ or $\mathrm{K}_{\mathrm{p} \text {, uu }}$ in wild-type FVB mice and MPO score ( $R^{2}$ for $\mathrm{K}_{\mathrm{p}}=0.108, R^{2}$ for $\left.\mathrm{K}_{\mathrm{p}, \text { uu }}=0.0000911\right)$. (D) Correlation between $\mathrm{K}_{\mathrm{p}}$ or $\mathrm{K}_{\mathrm{p} \text {,uu }}$ in tripleknockout (Mdrla/b $\left.\mathrm{b}^{-/} \mathrm{Bcrp}^{-/-}\right)$FVB mice and MPO score $\left(R^{2}\right.$ for $\mathrm{K}_{\mathrm{p}}=0.557, R^{2}$ for $\mathrm{K}_{\mathrm{p}, \mathrm{uu}}=0.433$ ). 
TABLE 5

The calculated scores based on physicochemical properties and the partition coefficients of brain

\begin{tabular}{|c|c|c|c|c|c|c|c|c|}
\hline Compound & CNS MPO Score $^{a}$ & clog D/sqrt(MW) & $\mathrm{K}_{\mathrm{p}, \text { brain }}$ in Publication & $\mathrm{K}_{\mathrm{p}, \text { brain }}$ in Wild-Type & $\mathrm{K}_{\mathrm{p}, \text { uu,brain }}$ in Wild-Type & $\mathrm{K}_{\mathrm{p}, \text { brain }}$ in TKO & $\mathrm{K}_{\mathrm{p}, \mathrm{uu}, \text { brain }}$ in TKO & DA \\
\hline AEE788 & 3.3 & 0.166 & NA & 0.066 & 0.029 & 1.86 & 0.80 & 28 \\
\hline Afatinib & 3.6 & 0.106 & $0.35^{b}$ & 0.268 & 0.048 & 2.41 & 0.43 & 9 \\
\hline AZD3759 & 3.7 & 0.180 & $0.89^{c}$ & 1.70 & 2.96 & 2.65 & 4.61 & 2 \\
\hline Dacomitinib & 2.8 & 0.163 & NA & 0.612 & 0.493 & 9.77 & 7.88 & 16 \\
\hline Erlotinib & 4.9 & 0.161 & $0.02^{\mathrm{d}} / 0.14^{e}$ & 0.060 & 0.130 & 0.20 & 0.44 & 3 \\
\hline Gefitinib & 4.0 & 0.172 & $0.21^{f} / 0.3^{g}$ & 0.358 & 0.103 & 2.20 & 0.63 & 6 \\
\hline Osimertinib & 2.8 & 0.135 & $1.78^{h}$ & 0.988 & 0.289 & 15.7 & 4.61 & 16 \\
\hline Vandetanib & 3.3 & 0.129 & $0.21^{i}$ & 0.635 & 0.138 & 12.2 & 2.65 & 19 \\
\hline
\end{tabular}

NA, not available.

${ }^{a}$ MPO, multiparameter optimization score calculated by using the method from Wager et al. (2016).

${ }^{b}$ Reported from van Hoppe et al. (2017).

${ }^{c}$ Reported from Xiong et al. (2017).

${ }^{d}$ In rat. Reported from Agarwal et al. (2013).

${ }^{e}$ In mouse. Reported from de Vries et al. (2012).

${ }^{f}$ In nude mice. Reported from Ballard et al. (2016).

${ }^{g}$ In FVB mice. Reported from Agarwal et al. (2010).

${ }^{h}$ In nude mice. Reported from Ballard et al. (2016).

${ }^{i}$ In FVB mice. Reported from Minocha et al. (2012).

brain penetration of a series of compounds with the same pharmacological target, and to understand a role of efflux transporters at the BBB in the brain distribution of these small-molecule therapeutics.

In the current study, we chose eight EGFR inhibitors that are in different stages of clinical development and vary in their known brain penetration. Five out of eight EGFR inhibitors (afatinib, erlotinib, gefitinib, osimertinib, and vandetanib) are approved anticancer drugs for various solid tumors, including NSCLC, a tumor that often metastasizes to the brain. However, none of these approved first and second generations of EGFR inhibitors are effective in patients with primary brain tumors, and have modest and variable efficacy in patients with metastatic brain tumors (Table 6), possibly due to their limited brain delivery across an intact blood-brain barrier. Therefore, there has been a critical need to develop a CNS penetrant EGFR inhibitor. Dacomitinib and AZD3759 are third generations of EGFR inhibitors. AZD3759 and osimertinib are reported to be CNS-penetrating EGFR inhibitors that are under clinical investigation for the treatment of advanced NSCLC. Clinical studies with AZD3759 demonstrated an objective response rate in over $80 \%$ of patients with NSCLC brain metastases (Ahn et al., 2017). Osimertinib has also shown promise in treating brain metastases (Goss et al., 2018). Dacomitinib has some limited efficacy in patients with metastatic NSCLC brain tumors harboring the T790M mutation (NCT01858389), and its efficacy in glioblastoma is currently under clinical investigation (NSC01112527).

It is possible that irreversible inhibitors, including dacomitinib, afatinib, and osimertinib, may not need as high of a brain partitioning as for reversible inhibitors to achieve the same pharmacodynamic effect. This is predicated on the turnover of the drug-receptor complex. If an EGFR inhibitor-receptor complex is rapidly turned over, the benefit of being an irreversible inhibitor can be lost. As such, it is still valuable to

TABLE 6

Summary of clinical information on the eight studied EGFR inhibitors

\begin{tabular}{|c|c|c|c|c|c|c|c|}
\hline Compound & $\begin{array}{l}\text { Clinical } \\
\text { Status }\end{array}$ & $\begin{array}{l}\text { Dose in } \\
\text { Patients }\end{array}$ & $\begin{array}{l}\text { Brain Penetration } \\
\text { (\% of CSF to Plasma } \\
\text { Levels) in Patient }\end{array}$ & $\begin{array}{c}\text { Brain Penetration (\% } \\
\text { of Brain-to-Plasma Ratio) } \\
\text { in Preclinical Model }\end{array}$ & $\begin{array}{l}\text { Response Rate in } \\
\text { Patients with Primary } \\
\text { Brain Tumor }\end{array}$ & $\begin{array}{l}\text { Response Rate in } \\
\text { Patients with Brain } \\
\text { Metastases }\end{array}$ & References \\
\hline & & $m g / d a y$ & & & $\%$ & $\%$ & \\
\hline AEE788 & Terminated & $50-800$ & ND & ND & GBM, stable disease (17) & ND & Reardon et al. (2012) \\
\hline Afatinib & Giotrif & 50 & 0.7 & ND & GBM, stable disease (14) & 35 & $\begin{array}{l}\text { Wind et al. (2014), } \\
\text { Hoffknecht et al. } \\
\text { (2015), Reardon et al. } \\
\text { (2015) }\end{array}$ \\
\hline AZD3759 & $\begin{array}{l}\text { Phase I } \\
\quad \text { (fast } \\
\text { review) }\end{array}$ & $100-1000$ & 111 & 282 & ND & 83 & $\begin{array}{l}\text { Zeng et al. (2015), Ahn } \\
\text { et al. (2017), Xiong } \\
\text { et al. (2017) }\end{array}$ \\
\hline Dacomitinib & Phase $2-3$ & $45 / 60$ & NA & NA & ND & $6.3^{a}$ & \\
\hline Erlotinib & Tarceva & 150 & $2.77-5.1$ & 13.7 & $\begin{array}{l}\text { GBM, PFS6 (3); first- } \\
\text { relapse GBM, OR (6.3) }\end{array}$ & $\begin{array}{l}82.4 \text { (EGFR } \\
\text { mutation) }\end{array}$ & $\begin{array}{l}\text { Raizer et al. (2010), } \\
\text { Togashi et al. (2010), } \\
\text { Yung et al. (2010), } \\
\text { Porta et al. (2011), } \\
\text { de Vries et al. (2012) }\end{array}$ \\
\hline Gefitinib & Iressa & $750-1000$ & $1.07-3.58$ & 27 & $\begin{array}{l}\text { Astrocytoma, overall } \\
\text { disease-control rate } \\
\text { (17.9); GBM, overall } \\
\text { disease-control rate } \\
(12.5)\end{array}$ & 27 & $\begin{array}{c}\text { Ceresoli et al. (2004), } \\
\text { Franceschi et al. (2007), } \\
\text { Chen et al. (2013) }\end{array}$ \\
\hline Osimertinib & Tagrisso & 80 & NA & 180 & ND & $54(\mathrm{~T} 790 \mathrm{M}+)$ & $\begin{array}{l}\text { Ballard et al. (2016), Goss } \\
\text { et al. (2018) }\end{array}$ \\
\hline Vandetanib & Caprelsa & 300 & $1.2-2.4$ & 21 & $\begin{array}{l}\text { GBM, objective response } \\
\text { rate }(12.5)\end{array}$ & ND & Kreisl et al. (2012) \\
\hline
\end{tabular}


assess the ability of CNS penetration of all of these drugs, both reversible and irreversible inhibitors, to predict potential efficacy in brain tumors.

The comparison of brain-to-plasma ratios determined by both cassette and discrete dosing confirms the absence of drug-drug interactions at the $\mathrm{BBB}$ in this series of compounds, similar to that reported previously by Liu et al. (2012). In the current study, brain-to-plasma ratios of a series of EGFR inhibitors obtained at 1 and 8 hours after dosing as a cassette were within a 2-fold range of the results from discrete dosing in both wild-type and transgenic mice that lacked both P-gp and Bcrp (TKO). The greatest difference in brain-to-plasma ratio between cassette and discrete dosing was observed with afatinib at 8 hours after dosing in wild-type mice, where the brain-to-plasma ratio estimate from the cassette study was overestimated about 5 times more than the value from discrete dosing. On the other hand, brain-to-plasma ratios of AEE788 after cassette dosing underestimated the values after discrete dosing at 1 hour post dose in wild-type mice and at 8 hours post dose in TKO mice. There were no consistent trends between these outliers, and therefore, this may represent experimental variability rather than a systematic trend related to the dosing strategies. Although both afatinib and AEE788 seem to be substrates of both P-gp and Bcrp, recognized from the values of the DA for these compounds, other compounds that are substrates of P-gp and Bcrp do not show any discrepancy between the results from cassette and discrete studies. In conclusion, overall, the results from cassette dosing match well with the results from discrete dosing. Thus, the close correlation between cassette- and discrete-dosing results confirms that no significant drug-drug interactions occur at the BBB with a dose of $1 \mathrm{mg} / \mathrm{kg}$, regardless of the efflux transporter liability.

The partition coefficients of brain $\left(\mathrm{K}_{\mathrm{p} \text {,brain }}\right)$ for each EGFR inhibitor were calculated from the AUC ratios of brain to plasma. In the current study, AUCs from time zero to the last time point were used for both plasma and brain without the extrapolation of AUC from the last time point to infinity, because the complete elimination phase was not reached until 16 hours after the dosing for some compounds. Therefore, AUCs from time zero to the last time point that concentrations were measured (i.e., 4 hours after the dosing for erlotinib, 16 hours after the dosing for all other compounds) were used for both plasma and brain to calculate the $\mathrm{K}_{\mathrm{p} \text {,brain }}$ for each EGFR inhibitor. When the calculated $\mathrm{K}_{\mathrm{p} \text {,brain }}$ values from this study were compared with previously reported $\mathrm{K}_{\mathrm{p} \text {,brain }}$ (Table 5), values were within 2-fold, except for vandetanib. Based on a $K_{p}$,brain over 0.5 in wild-type mice, AZD3759, dacomitinib, osimertinib, and vandetanib can be classified as brain penetrant EGFR inhibitors.

The free partition coefficients were calculated with the free fractions in plasma and brain homogenate determined by rapid equilibrium dialysis in the current study. According to our findings, four compounds that have the highest free brain partition coefficients were the brain penetrant EGFR inhibitors based on their $\mathrm{K}_{\mathrm{p} \text {,brain }}$, even though the order of the values were slightly different from the total concentration based on $\mathrm{K}_{\mathrm{p} \text {,brain. }}$ The equilibrium dialysis is one of the most common ways to determine the free fractions of compounds and the most efficient method with reasonable predictability (Becker and Liu, 2006). However, there has been a concern about nonspecific adsorption to the device, especially the compounds with low free fractions (Riccardi et al., 2015), and a novel method to determine the free fractions in highly bound compounds was proposed recently (Kalvass et al., 2018). Therefore, considering the limitations with the current method used in the study, further evaluations of the free fractions and $\mathrm{K}_{\mathrm{p} \text {,uu }}$ for these eight EGFR inhibitors are needed using different methods.

Previous research on the efflux transporter liability of these EGFR inhibitors has shown that afatinib, erlotinib, gefitinib, osimertinib, and vandetanib are substrates of both P-gp and Bcrp (Agarwal et al., 2010, 2013; Minocha et al., 2012; Ballard et al., 2016). On the other hand,
AZD3759 has been reported to not be a substrate of either P-gp or Bcrp. The $\mathrm{K}_{\mathrm{p} \text {,brain }}$ calculated in the current study agreed with the previous results in that the compounds known to be substrates of efflux transporters showed much higher brain partition coefficient values in $\mathrm{Mdr} 1 \mathrm{a} / \mathrm{b}^{-/-} \mathrm{Bcrp}^{-1-}$ mice (TKO) when compared with wild-type mice. AEE788 and dacomitinib, which have no previous reports regarding their efflux transporter liability, were shown to be substrates of both/ either P-gp and/or Bcrp in this study (see the DA values in Table 4). The $\mathrm{K}_{\mathrm{p} \text {,brain }}$ in TKO for AZD3759 was similar to the value in wild-type, with a DA of 1.56, which indicates neither P-gp nor Bcrp plays a major role in the brain distribution of AZD3759, as was previously reported (Zeng et al., 2015; Yang et al., 2016). In conclusion, seven out of eight EGFR inhibitors investigated in the current study were shown to be substrates of both/either P-gp and/or Bcrp based on the DA calculated with the brain partition coefficients in wild-type and TKO mice, and AZD3759 is the only exception that is not a substrate of both P-gp and Bcrp.

The brain penetration of each EGFR inhibitor was examined within a single animal to assess the brain penetrability of each drug under the same physiologic conditions by using a "visual heat map." Rank orders of brain-to-plasma ratios at a single time point were consistent until 2 hours after dosing in both wild-type and TKO mice. There can be several reasons for having less consistent rank orders after 2 hours. One explanation is that the systemic clearances and the brain distributional clearances, or the combination of the two, that influence the brain-toplasma ratios may be different in individual animals, and this difference would be accentuated at late times. Another reason can be that some compounds are somewhat excluded from the rank calculation due to low concentration measured near the lowest limit of quantitation. Importantly, the ability of each of these inhibitors to distribute into the brain within a single animal seems to be consistent between animals, even though some physiologic conditions may be slightly different in each animal.

The brain distribution, including the BBB permeability of a drug, can be related to the physicochemical properties of a compound when passive diffusion dominates drug transport processes. Importantly, molecular weight, lipophilicity $(\log \mathrm{P}$ or $\log \mathrm{D})$, hydrogen bond donor and acceptor count, and topological polar surface area of a molecule are considered to be crucial properties to determine the intrinsic permeability and brain distribution (Rankovic, 2015; Heffron, 2016). Among these crucial characteristics of a molecule, clog D and molecular size (weight) were believed to be two key factors that determine the ability to cross the BBB (Oldendorf, 1974; Levin, 1980). It has been shown that there is a reasonable correlation between the calculated ratios of clog $\mathrm{D}$ and square root of molecular weight and the permeability in the brain capillaries, using in situ perfusion as a measure of permeability (Levin, 1980). Recently, the CNS MPO desirability tool has been proposed to predict CNS penetration and understand the relationship between physicochemical properties and the drug distribution in the CNS (Wager et al., 2010, 2016). In the current study, we found that there was a lack of correlation between the brain distribution of a compound defined by $\mathrm{K}_{\mathrm{p} \text {,brain }}$ and the physicochemical properties of a set of EGFR inhibitors. Even if nonspecific protein binding or the effect of major transporters, P-gp and Bcrp, was considered by using the free partition coefficient $\left(\mathrm{K}_{\mathrm{p} \text {,uu }}\right)$ or transporter-deficient mice, no predictive correlation between brain penetrability and physicochemical properties of these compounds was found (Fig. 4).

In conclusion, the current study indicates that cassette dosing can be a useful method to determine the brain distribution of a set of molecularly targeted anticancer therapeutics that share the same target-in this case, EGFR. The concordance of the brain-to-plasma ratios at a single time point following either cassette dosing or discrete dosing validated that both methods are comparable, especially for rank order screening. A 
cassette-dosing strategy is useful, not only because of cost and time efficiency but also because of the ability to directly compare drug brain penetrability among a set of compounds within a single animal. The rank orders of the brain-to-plasma ratios in a single animal were consistent with the rank orders of $\mathrm{K}_{\mathrm{p} \text {,brain }}$ calculated by AUC ratios of brain to plasma. Therefore, the cassette-dosing strategy can be useful for candidate selection with respect to brain distribution. Among this set of EGFR inhibitors examined in the current study, AZD3759, osimertinib, vandetanib, and dacomitinib have superior brain penetration (over $50 \%$ of corresponding plasma concentration). These brain penetrant EGFR inhibitors may have value for the treatment of tumors located in the brain and should be considered for future clinical trials.

\section{Authorship Contributions}

Participated in research design: Kim, Laramy, Sarkaria, Elmquist. Conducted experiments: Kim, Laramy, Mohammad, Talele, Fisher. Performed data analysis: Kim, Sarkaria, Elmquist.

Wrote or contributed to the writing of the manuscript: Kim, Sarkaria, Elmquist.

\section{References}

Agarwal S, Manchanda P, Vogelbaum MA, Ohlfest JR, and Elmquist WF (2013) Function of the blood-brain barrier and restriction of drug delivery to invasive glioma cells: findings in an orthotopic rat xenograft model of glioma. Drug Metab Dispos 41:33-39.

Agarwal S, Sane R, Gallardo JL, Ohlfest JR, and Elmquist WF (2010) Distribution of gefitinib to the brain is limited by P-glycoprotein (ABCB1) and breast cancer resistance protein (ABCG2) mediated active efflux. J Pharmacol Exp Ther 334:147-155.

Ahn MJ, Kim DW, Cho BC, Kim SW, Lee JS, Ahn JS, Kim TM, Lin CC, Kim HR, John T, et al (2017) Activity and safety of AZD3759 in EGFR-mutant non-small-cell lung cancer with CNS metastases (BLOOM): a phase 1, open-label, dose-escalation and dose-expansion study. Lancet Respir Med 5:891-902.

Ballard P, Yates JW, Yang Z, Kim DW, Yang JC, Cantarini M, Pickup K, Jordan A, Hickey M, Grist M, et al. (2016) Preclinical comparison of osimertinib with other EGFR-TKIs in EGFRmutant NSCLC brain metastases models, and early evidence of clinical brain metastases activity. Clin Cancer Res 22:5130-5140.

Becker S and Liu X (2006) Evaluation of the utility of brain slice methods to study brain penetration. Drug Metab Dispos 34:855-861.

Bertotti A, Burbridge MF, Gastaldi S, Galimi F, Torti D, Medico E, Giordano S, Corso S, RollandValognes G, Lockhart BP, et al. (2009) Only a subset of Met-activated pathways are required to sustain oncogene addiction [published correction appears in Sci Signal (2009) 2:er11]. Sci Signal 2:ra80.

Brennan CW, Verhaak RG, McKenna A, Campos B, Noushmehr H, Salama SR, Zheng S, Chakravarty D, Sanborn JZ, Berman SH, et al.; TCGA Research Network (2013) The somatic genomic landscape of glioblastoma. Cell 155:462-477.

Ceresoli GL, Cappuzzo F, Gregorc V, Bartolini S, Crinò L, and Villa E (2004) Gefitinib in patients with brain metastases from non-small-cell lung cancer: a prospective trial. Ann Oncol 15: 1042-1047.

Chen Y, Wang M, Zhong W, and Zhao J (2013) Pharmacokinetic and pharmacodynamic study of Gefitinib in a mouse model of non-small-cell lung carcinoma with brain metastasis. Lung Cancer 82:313-318

Cooray HC, Blackmore CG, Maskell L, and Barrand MA (2002) Localisation of breast cancer resistance protein in microvessel endothelium of human brain. Neuroreport 13:2059-2063.

Cordon-Cardo C, O'Brien JP, Casals D, Rittman-Grauer L, Biedler JL, Melamed MR, and Bertino JR (1989) Multidrug-resistance gene (P-glycoprotein) is expressed by endothelial cells at bloodbrain barrier sites. Proc Natl Acad Sci USA 86:695-698.

Cross DA, Ashton SE, Ghiorghiu S, Eberlein C, Nebhan CA, Spitzler PJ, Orme JP, Finlay MR, Ward RA, Mellor MJ, et al. (2014) AZD9291, an irreversible EGFR TKI, overcomes T790Mmediated resistance to EGFR inhibitors in lung cancer. Cancer Discov 4:1046-1061.

de Vries NA, Buckle T, Zhao J, Beijnen JH, Schellens JH, and van Tellingen O (2012) Restricted brain penetration of the tyrosine kinase inhibitor erlotinib due to the drug transporters P-gp and BCRP. Invest New Drugs 30:443-449.

Doroshow JH (2005) Targeting EGFR in non-small-cell lung cancer. $N$ Engl J Med 353:200-202.

Engelman JA, Zejnullahu K, Gale CM, Lifshits E, Gonzales AJ, Shimamura T, Zhao F, Vincent PW, Naumov GN, Bradner JE, et al. (2007) PF00299804, an irreversible pan-ERBB inhibitor, is effective in lung cancer models with EGFR and ERBB2 mutations that are resistant to gefitinib. Cancer Res 67:11924-11932.

Franceschi E, Cavallo G, Lonardi S, Magrini E, Tosoni A, Grosso D, Scopece L, Blatt V, Urbini B, Pession A, et al. (2007) Gefitinib in patients with progressive high-grade gliomas: a multicentre phase II study by Gruppo Italiano Cooperativo di Neuro-Oncologia (GICNO). Br J Cancer 96 1047-1051.

Goss G, Tsai CM, Shepherd FA, Ahn MJ, Bazhenova L, Crinò L, de Marinis F, Felip E, Morabito A. Hodge R, et al. (2018) CNS response to osimertinib in patients with T790M-positive advanced NSCLC: pooled data from two phase II trials. Ann Oncol 29:687-693.

Heffron TP (2016) Small molecule kinase inhibitors for the treatment of brain cancer. J Med Chem 59:10030-10066

Hoffknecht P, Tufman A, Wehler T, Pelzer T, Wiewrodt R, Schütz M, Serke M, StöhlmacherWilliams J, Märten A, Maria Huber R, et al.; Afatinib Compassionate Use Consortium (ACUC) (2015) Efficacy of the irreversible ErbB family blocker afatinib in epidermal growth factor receptor (EGFR) tyrosine kinase inhibitor (TKI)-pretreated non-small-cell lung cancer patients with brain metastases or leptomeningeal disease. J Thorac Oncol 10:156-163.

Huang PH, Xu AM, and White FM (2009) Oncogenic EGFR signaling networks in glioma. Sci Signal 2:re6.
Kalvass JC and Maurer TS (2002) Influence of nonspecific brain and plasma binding on CNS exposure: implications for rational drug discovery. Biopharm Drug Dispos 23:327-338.

Kalvass JC, Phipps C, Jenkins GJ, Stuart P, Zhang X, Heinle L, Nijsen MJMA, and Fischer V (2018) Mathematical and experimental validation of flux dialysis method: an improved approach to measure unbound fraction for compounds with high protein binding and other challenging properties. Drug Metab Dispos 46:458-469.

Kawamura K, Yamasaki T, Yui J, Hatori A, Konno F, Kumata K, Irie T, Fukumura T, Suzuki K, Kanno I, et al. (2009) In vivo evaluation of P-glycoprotein and breast cancer resistance protein modulation in the brain using [(11)C]gefitinib. Nucl Med Biol 36:239-246.

Krawczyk P, Kowalski DM, Ramlau R, Kalinka-Warzocha E, Winiarczyk K, Stencel K, Powrózek T, Reszka K, Wojas-Krawczyk K, Bryl M, et al. (2017) Comparison of the effectiveness of erlotinib, gefitinib, and afatinib for treatment of non-small cell lung cancer in patients with common and rare EGFR gene mutations. Oncol Lett 13:4433-4444.

Kreisl TN, McNeill KA, Sul J, Iwamoto FM, Shih J, and Fine HA (2012) A phase I/II trial of vandetanib for patients with recurrent malignant glioma. Neuro-oncol 14:1519-1526.

Levin VA (1980) Relationship of octanol/water partition coefficient and molecular weight to rat brain capillary permeability. J Med Chem 23:682-684.

Liu X, Ding X, Deshmukh G, Liederer BM, and Hop CE (2012) Use of the cassette-dosing approach to assess brain penetration in drug discovery. Drug Metab Dispos 40:963-969.

Lockman PR, Mittapalli RK, Taskar KS, Rudraraju V, Gril B, Bohn KA, Adkins CE, Roberts A, Thorsheim HR, Gaasch JA, et al. (2010) Heterogeneous blood-tumor barrier permeability determines drug efficacy in experimental brain metastases of breast cancer. Clin Cancer Res 16: 5664-5678.

Manitpisitkul P and White RE (2004) Whatever happened to cassette-dosing pharmacokinetics? Drug Discov Today 9:652-658.

McCoach CE, Berge EM, Lu X, Barón AE, and Camidge DR (2016) A brief report of the status of central nervous system metastasis enrollment criteria for advanced non-small cell lung cancer clinical trials: a review of the ClinicalTrials.gov trial registry. J Thorac Oncol 11:407-413.

Minocha M, Khurana V, Qin B, Pal D, and Mitra AK (2012) Co-administration strategy to enhance brain accumulation of vandetanib by modulating P-glycoprotein (P-gp/Abcb1) and breast cancer resistance protein (Bcrp1/Abcg2) mediated efflux with m-TOR inhibitors. Int J Pharm 434 306-314.

Ohgaki H and Kleihues P (2007) Genetic pathways to primary and secondary glioblastoma. Am J Pathol 170:1445-1453.

Oldendorf WH (1974) Lipid solubility and drug penetration of the blood brain barrier. Proc Soc Exp Biol Med 147:813-815.

Porta R, Sánchez-Torres JM, Paz-Ares L, Massutí B, Reguart N, Mayo C, Lianes P, Queralt C, Guillem V, Salinas P, et al. (2011) Brain metastases from lung cancer responding to erlotinib: the importance of EGFR mutation. Eur Respir J 37:624-631.

Raizer JJ, Abrey LE, Lassman AB, Chang SM, Lamborn KR, Kuhn JG, Yung WK, Gilbert MR, Aldape KD, Wen PY, et al.; North American Brain Tumor Consortium (2010) A phase I trial of erlotinib in patients with nonprogressive glioblastoma multiforme postradiation therapy, and recurrent malignant gliomas and meningiomas. Neuro-oncol 12:87-94.

Rangachari D, Yamaguchi N, VanderLaan PA, Folch E, Mahadevan A, Floyd SR, Uhlmann EJ, Wong ET, Dahlberg SE, Huberman MS, et al. (2015) Brain metastases in patients with EGFRmutated or ALK-rearranged non-small-cell lung cancers. Lung Cancer 88:108-111.

Rankovic Z (2015) CNS drug design: balancing physicochemical properties for optimal brain exposure. J Med Chem 58:2584-2608.

Reardon DA, Conrad CA, Cloughesy T, Prados MD, Friedman HS, Aldape KD, Mischel P, Xia J, DiLea C, Huang J, et al. (2012) Phase I study of AEE788, a novel multitarget inhibitor of ErbBand VEGF-receptor-family tyrosine kinases, in recurrent glioblastoma patients. Cancer Chemother Pharmacol 69:1507-1518.

Reardon DA, Nabors LB, Mason WP, Perry JR, Shapiro W, Kavan P, Mathieu D, Phuphanich S, Cseh A, Fu Y, et al.; BI 120036 Trial Group and the Canadian Brain Tumour Consortium (2015) Phase I/randomized phase II study of afatinib, an irreversible ErbB family blocker, with or without protracted temozolomide in adults with recurrent glioblastoma. Neuro-oncol 17:430-439.

Riccardi K, Cawley S, Yates PD, Chang C, Funk C, Niosi M, Lin J, and Di L (2015) Plasma protein binding of challenging compounds. J Pharm Sci 104:2627-2636.

Rich JN, Reardon DA, Peery T, Dowell JM, Quinn JA, Penne KL, Wikstrand CJ, Van Duyn LB, Dancey JE, McLendon RE, et al. (2004) Phase II trial of gefitinib in recurrent glioblastoma. $J$ Clin Oncol 22:133-142.

Sarkaria JN, Hu LS, Parney IF, Pafundi DH, Brinkmann DH, Laack NN, Giannini C, Burns TC, Kizilbash SH, Laramy JK, et al. (2018) Is the blood-brain barrier really disrupted in all glioblastomas? A critical assessment of existing clinical data. Neuro-oncol 20: 184-191.

Seshacharyulu P, Ponnusamy MP, Haridas D, Jain M, Ganti AK, and Batra SK (2012) Targeting the EGFR signaling pathway in cancer therapy. Expert Opin Ther Targets 16:15-31.

Shinojima N, Tada K, Shiraishi S, Kamiryo T, Kochi M, Nakamura H, Makino K, Saya H, Hirano $\mathrm{H}$, Kuratsu J, et al. (2003) Prognostic value of epidermal growth factor receptor in patients with glioblastoma multiforme. Cancer Res 63:6962-6970.

Solca F, Dahl G, Zoephel A, Bader G, Sanderson M, Klein C, Kraemer O, Himmelsbach F, Haaksma E, and Adolf GR (2012) Target binding properties and cellular activity of afatinib (BIBW 2992), an irreversible ErbB family blocker. J Pharmacol Exp Ther 343: $342-350$

Togashi Y, Masago K, Fukudo M, Terada T, Fujita S, Irisa K, Sakamori Y, Kim YH, Mio T, Inui K, et al. (2010) Cerebrospinal fluid concentration of erlotinib and its active metabolite OSI-420 in patients with central nervous system metastases of non-small cell lung cancer. J Thorac Oncol 5:950-955.

van den Bent MJ, Brandes AA, Rampling R, Kouwenhoven MC, Kros JM, Carpentier AF, Clement PM, Frenay M, Campone M, Baurain JF, et al. (2009) Randomized phase II trial of erlotinib versus temozolomide or carmustine in recurrent glioblastoma: EORTC brain tumor group study 26034. J Clin Oncol 27:1268-1274.

van Hoppe S, Sparidans RW, Wagenaar E, Beijnen JH, and Schinkel AH (2017) Breast cancer resistance protein (BCRP/ABCG2) and P-glycoprotein (P-gp/ABCB1) transport afatinib and restrict its oral availability and brain accumulation. Pharmacol Res 120:43-50.

Wager TT, Hou X, Verhoest PR, and Villalobos A (2010) Moving beyond rules: the development of a central nervous system multiparameter optimization (CNS MPO) approach to enable alignment of druglike properties. ACS Chem Neurosci 1:435-449.

Wager TT, Hou X, Verhoest PR, and Villalobos A (2016) Central nervous system multiparameter optimization desirability: application in drug discovery. ACS Chem Neurosci 7: $767-775$. 
Weber B, Winterdahl M, Memon A, Sorensen BS, Keiding S, Sorensen L, Nexo E, and Meldgaard P (2011) Erlotinib accumulation in brain metastases from non-small cell lung cancer: visualization by positron emission tomography in a patient harboring a mutation in the epidermal growth factor receptor. $J$ Thorac Oncol 6:1287-1289.

Wind S, Giessmann T, Jungnik A, Brand T, Marzin K, Bertulis J, Hocke J, Gansser D, and Stopfer P (2014) Pharmacokinetic drug interactions of afatinib with rifampicin and ritonavir. Clin Drug Investig 34:173-182.

Xiong S, Xue M, Mu Y, Deng Z, Sun P, and Zhou R (2017) Determination of AZD3759 in rat plasma and brain tissue by LC-MS/MS and its application in pharmacokinetic and brain distribution studies. J Pharm Biomed Anal 140:362-366.

Yang Z, Guo Q, Wang Y, Chen K, Zhang L, Cheng Z, Xu Y, Yin X, Bai Y, Rabbie S, et al. (2016) AZD3759, a BBB-penetrating EGFR inhibitor for the treatment of EGFR mutant NSCLC with CNS metastases. Sci Transl Med 8:368ra172.
Yung WK, Vredenburgh JJ, Cloughesy TF, Nghiemphu P, Klencke B, Gilbert MR, Reardon DA and Prados MD (2010) Safety and efficacy of erlotinib in first-relapse glioblastoma: a phase II open-label study. Neuro-oncol 12:1061-1070.

Zeng Q, Wang J, Cheng Z, Chen K, Johnström P, Varnäs K, Li DY, Yang ZF, and Zhang X (2015) Discovery and evaluation of clinical candidate AZD3759, a potent, oral active, central nervous systempenetrant, epidermal growth factor receptor tyrosine kinase inhibitor. J Med Chem 58:8200-8215.

Address correspondence to: William F. Elmquist, Department of Pharmaceutics, University of Minnesota, 308 Harvard Street SE, Minneapolis, MN 55455. E-mail: elmqu011@umn.edu 